\title{
Research on the Control of Out-of-Round Wheel Profiles of High-Speed Railway Derived from Numerical Simulations
}

\author{
http://dx.doi.org/10.3991/ijoe.v9iS6.2924 \\ Ying Song, Zhichen Wang* and Yingming Shen \\ Shijiazhuang Tiedao University, Shijiazhuang, China
}

\begin{abstract}
Periodic non-roundness of railway wheels will cause a series of variety on vehicle/track coupling system dynamic responses. A coupling dynamics model of railway vehicle with out-of-round wheels and track was built based on ADAMS/Rail. The effect of periodic non-roundness of wheel on the dynamical behavior of the vehicle system was analyzed. The numerical results regarding the misalignments of the vehicle and wheelset, the vertical wheel/rail contact forces and the reduction in the wheelset loading are presented under the conditions in which the wheels are in out-of-round and the train speed is from $200 \mathrm{~km} / \mathrm{h}$ to 350 $\mathrm{km} / \mathrm{h}$. The results show that the dynamical vertical wheel/rail interaction forces are much related to the wheel out-of-roundness status. The critical range of the wheel outof-roundness is determined according to the traditional criterion of wheelset loading reduction for safely running estimation. It's pointed out that out-of-round railway wheels can be detected by wheel/rail interaction force real-time monitoring system to guarantee safety and to minimize costs for repair and maintenance.
\end{abstract}

Index Terms-High speed train wheelset; out-of-round wheel; wheel/rail impact vibration; ADAMS/Rail

\section{INTRODUCTION}

Imperfections on wheel tread are basically divided into two types: defects along part of the wheel circumference, and defects around the complete wheel circumference[1]. These are both regarded as types of Wheel out-of-round (OOR) phenomena. The former includes imperfections such as wheelflat, local spall, etc. These two common types of local OOR wheels which mainly result from braking thermal damage and rolling contact fatigue cracking. The latter includes wheel corrugation and polygonal wheel. This type of OOR has a periodic radical irregularity around the wheel circumference. Non-roundness of railway wheels causes various vehicle-track coupling system dynamic responses, which has a detrimental influence on both the track and vehicle components [2 4]. Now that the speed of modern trains has become higher and newer building substructures have become stiffer, measurements show that small radius deviations have enlarged rapidly of some typical OOR shapes. In order to guarantee safety and stability, and to minimize costs for repair and maintenance, it is desirable to determine a range for acceptable roundness values and to detect, remove, and repair defective wheels in time.

Regarding these problems, many published papers have reported relevant results including the dynamic influence and development mechanism of OOR[5 8]. However, the high-speed railway in China develops relatively late, the present research mainly focuses on local OOR wheels. The range of periodic out-of-roundness which is beneficial to detect, repair, and remove non-round wheels promptly has not been generally known thus far. Since it is desirable to remove all wheels that cause additional damage to trains and hacks, new criteria need to be developed as well as new methods for detection of wheel defects. In this paper, a vehicle-track spatial coupling dynamics model with periodic OOR wheels is established to simulate the dynamic influence of periodic OOR in high speed. It put forward safety threshold of periodic OOR wheels. The view that it is of important significance to establish wheel/rail force real-time monitoring system is expanded, so that OOR wheels can be detected and replaced promptly.

\section{Simulation Model}

In order to investigate the influence of different types of railway wheel OOR on the vehicle-track coupling system dynamic responses, a vehicle-track spatial coupling dynamics model is applied, based on the theory of Zhai. The simulation model of the whole-passenger car and the track is shown in Fig. 1. The whole-passenger car considered is equipped with a bogie with two wheelsets and double suspension systems. The discretely supported rails are simplified as Euler-beam with limit length lying on an elastic point support. Sleepers are treated as rigid. Each rail pad is modeled as a discrete linear elastic spring and a viscous damper in parallel. Ballast and subgrade are also modeled by springs and dampers in parallel. An illustration of the key part of modeling vehicle-track coupling dynamics is the wheel/rail contact calculation model which has a direct influence on the precision and the speed of the computing analysis. In this paper, the normal forces of wheel-rail are calculated by a Hertzian nonlinear contact spring with a unilateral restraint; The creep forces of wheel-rail are decided by the nonlinear creep theory of Shen. The creepages and creep forces are concerned with the parameters of contact geometry of the wheel/rail. It is emphasized that the rolling circle is not ideal circle. OOR shapes are modelled by a variable radius around the tread as a function of the angle of wheel rotation. Errors in roundness of wheels is introduced as increment $\Delta r$ to the distance to the rotational center. $\Delta r$ is considered as a function of the angle $\varphi$ between the initial contact radius of the OOR railway wheel and the horizontal axis at time $t$, as shown in Fig. 2. The corresponding program has been compiled, which 
modifies the initial nominal contact radius at each time step, and the contact geometry of the wheel/rail are obtained. Vehicle-track coupling system dynamic responses are solved with explicit integration methods.

\section{SAFETy Limit OF WHEEL TREAD IRREGUlarities}

\section{A. Long Local Defects}

This is a deviation of the wheel radius that is present over a local part of the tread due to rolling contact fatigue. The wavelengths of irregularity range from $400 \mathrm{~mm}$ to $800 \mathrm{~mm}$, while the amplitudes range from $0.5 \mathrm{~mm}$ to $2.0 \mathrm{~mm}$. This type of OOR is classified as single harmonic out-of-roundness, double harmonics out-of-roundness, continuous harmonic out-of-roundness and saddle out-ofroundness, examples are shown in Fig. 3. The instant rolling radii error $\Delta r(\varphi)$ can be expressed as follows.

$$
\Delta r=\left\{\begin{array}{cc}
\frac{1}{2} a\left(1-\cos \frac{2 \pi R \varphi}{L}\right) & 0 \leq \varphi \leq \frac{n L}{R} \\
0 & \frac{n L}{R}<\varphi \leq 2 \pi
\end{array}\right.
$$

Where, single harmonic: $n=1$; double harmonic: $n=2$; continuous harmonic: ${ }^{n=2 \pi R / L}$; $a$ : OOR amplitude, $L$ : OOR wavelength.

The influence of long local wheel defects on the vertical dynamic wheel-rail contact force and train response is investigated. It is different from isolated wheel flats which cause severe repeated impact loads with high frequency contents. For the long local defect in Fig. 3, it

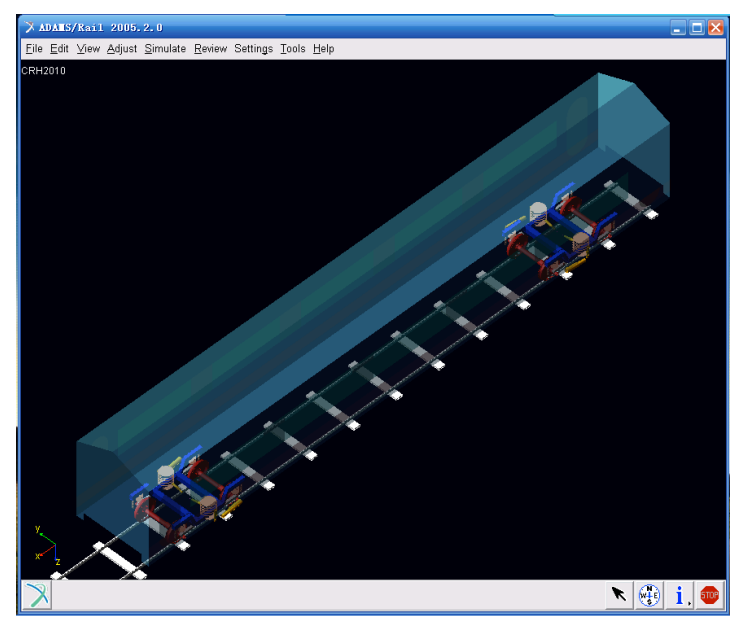

Figure 1. Three-dimensional train-track simulation mode

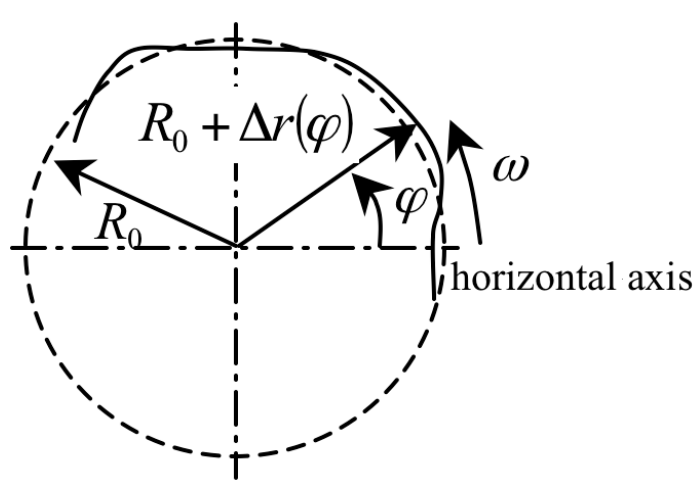

Figure 2. Errors in roundness of wheels leads to periodic excitation of vehicle and track system. A study to investigate the respective influence of long local defect wavelength and amplitude on impact force at train speed $300 \mathrm{~km} / \mathrm{h}$ is performed. The calculated wheel-rail peak contact forces versus wavelengths are shown in Fig. 4 , and the amplitude is kept constant at $0.5 \mathrm{~mm}$. The peak contact forces versus amplitudes with train speed range from $250 \mathrm{~km} / \mathrm{h}$ to $350 \mathrm{~km} / \mathrm{h}$ are shown in Fig 5 . It is observed that the maximum contact force is reduced when the wavelength of long local defect is increased, and it is increased when the amplitude and train speed are increased. The influence of amplitude is larger than that of train speed. For example, the impact load maximum is found to increase $45.9 \%$ with train speed increasing from $200 \mathrm{~km} / \mathrm{h}$ to $300 \mathrm{~km} / \mathrm{h}$, when the amplitude is kept constant at $1.0 \mathrm{~mm}$. While the corresponding value of the peak contact force increases $77.8 \%$ with amplitude increasing from $1 \mathrm{~mm}$ to $2 \mathrm{~mm}$ at train speed $350 \mathrm{~km} / \mathrm{h}$. The optimum impact load threshold level, where out-ofround wheels with long local defects, is found to be less than $250 \mathrm{kN}$. It is concluded that the threshold limit of out-of-roundness for long local defect wheel is $0.95 \mathrm{~mm}$ at train speed $250 \mathrm{~km} / \mathrm{h}, 0.8 \mathrm{~mm}$ at train speed $300 \mathrm{~km} / \mathrm{h}$, and $0.7 \mathrm{~mm}$ at train speed $350 \mathrm{~km} / \mathrm{h}$ as shown in Fig. 5 .

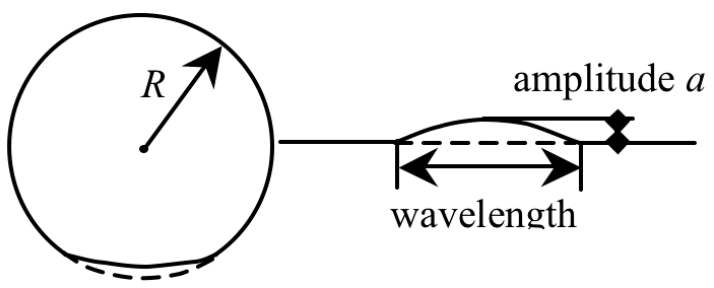

(a) single harmonic

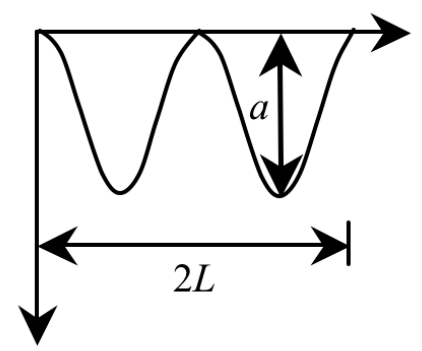

(b) double harmonics

Figure 3. Long local defect of railway wheel

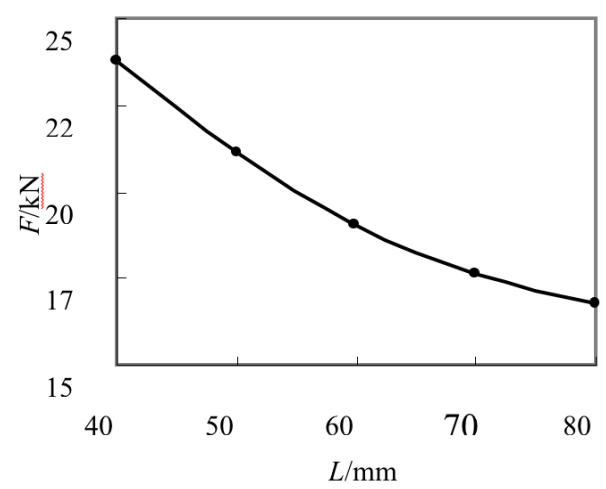

Figure 4. Impact loads from wheels with long local defects versus OOR wavelength 


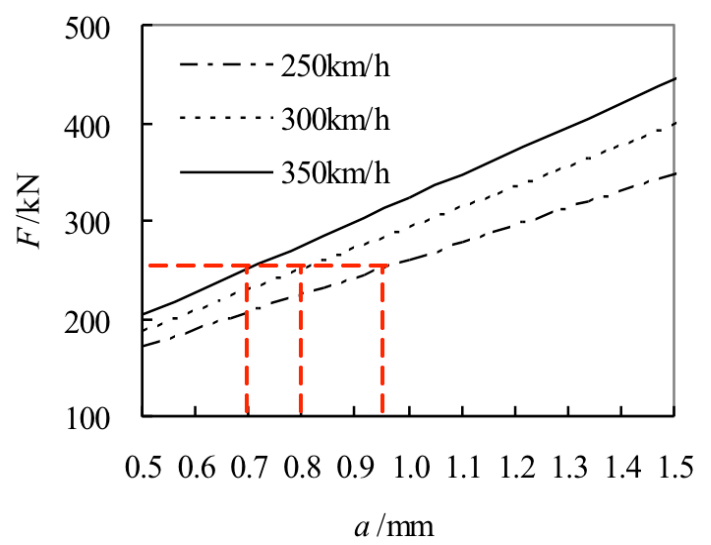

Figure 5. Impact loads from wheels with long local defects versus train speed

\section{B. Wheel Polygonalization}

Wheel Polygonalization is a periodic OOR of long wavelength on the running surface around the complete wheel circumference. This type of OOR has a periodic irregularity around the wheel circumference superimposed on the constant radius. The wavelength of the irregularity ranges from $0.1 \mathrm{~m}$ to approximately one wheel circumference, while the amplitude is of the order of $1 \mathrm{~mm}^{[7,8]}$. Examples of periodic OOR with one, three and four periods around the wheel circumference have been found on wheels from ICE trains in Germany. The initially OOR enlarges rapidly during further operation. For the periodic OOR, a sinusoidal function is used to describe the harmonic deviation in wheel radius from the nominal constant one. The instant rolling radii error $\Delta r(\varphi)$ can be expressed as

$$
\Delta r=a_{\theta} \sin (\theta \times \varphi), \theta=1,2,3 \ldots 20
$$

Where, ${ }^{\theta}$ is OOR order defined as the number of periods around the wheel circumference, it ranges between 1 to 20 (first, second, third, fourth, ....... and $20^{\text {th }}$ OOR order). ${ }^{a_{\theta}}$ is OOR amplitude which is defined here to be half the difference between the maximum and minimum value of a nearly sinusoidal curve.

The main study is the effect of wheel polygonalization with OOR order from 2 to 20 . The second order periodic polygonalization of railway wheels is wheel ovalization. The difference between the length of the semi-major axis and the semi-minor axis is defined as the ovalization extent ${ }^{a}$ as described in (2). The following cases are calculated: Case 1 corresponds to the condition that the ovalization extent ${ }^{a}$ varies between $0.4 \sim 2.0 \mathrm{~mm}$, and train speed keeps constant at $300 \mathrm{~km} / \mathrm{h}$. Case 2 corresponds to the condition that train speed ranges from $250 \mathrm{~km} / \mathrm{h}$ to 350 $\mathrm{km} / \mathrm{h}$ with the ovalization extent ${ }^{a} 1.4 \mathrm{~mm}$. For brevity, only parts of the results of the two cases are plotted. Case 1 is shown in Fig. 6. It is concluded that such defects often lead to harmonic impact loads, and the wavelength is half of the whole rolling circumference. The maximum of dynamic wheel-rail contact forces and the frequency of that increase with increasing speed. The wheel separates from rail instantly when train speed reaches at $300 \mathrm{~km} / \mathrm{h}$. Impact loads increase with increasing size of wheel ovalization extent. The wheel separates from rail instantly when ovalization extent ${ }^{a}$ reaches at $1.4 \mathrm{~mm}$. The relationship between wheel unloading rate and ovalization extent is shown in Fig. 7. According to the maximum allowed wheel unloadieng rate $\Delta P / \bar{P}=0.6$, it is concluded that safety threshold of wheel ovalization is $0.94 \mathrm{~mm}$ at train speed $300 \mathrm{~km} / \mathrm{h}$, the peak impact load in this case is 117 $\mathrm{kN}$.

The effects of other orders $\left({ }^{\theta} \geq 3\right)$ of periodic polygonal railway wheels have also been studied. They also give rise to periodic vibration of vehicle-track coupling system, and lead to increased wheel unloading rate. Impact loads are found to vary strongly with train speed, and to increase with increasing OOR amplitude of the wheel polygonalization. In Fig.8, the relationship between wheel unloading rate and OOR amplitude at train speed of $300 \mathrm{~km} / \mathrm{h}$ is shown, with OOR order $\theta$ from 3 to 6 . Simulation results show that the OOR amplitude thresholds are $0.25 \mathrm{~mm}$ at $\theta=6,0.35 \mathrm{~mm}$ at $\theta=5,0.5 \mathrm{~mm}$ at $\theta=4$, and $0.7 \mathrm{~mm}$ at $\theta=3$ respectively when the maximum allowed wheel unloading rate is 0.6 , and at the same time, the peak impact load reaches $120 \mathrm{kN}$. The OOR amplitude thresholds of polygonal wheels with OOR order $\theta>6$ are less than $0.2 \mathrm{~mm}$.

\section{Criterion for OOR wheel identification}

The objective of the present study is to quantify the vertical wheel-rail contact force for different types of OOR. The influences of other examples of OOR include wheelflats with various combinations of lengths and depths are also investigated based on the simulation model of vehicle-track coupling system. Criterion for OOR wheel identification is put forward according to simulation results as shown in Table I. The view that it is of important significance to establish wheel/rail force real-time monitoring system is expanded, so that abnormal conditions caused by OOR wheels can be detected in time, to ensure high-speed railway traffic safety.

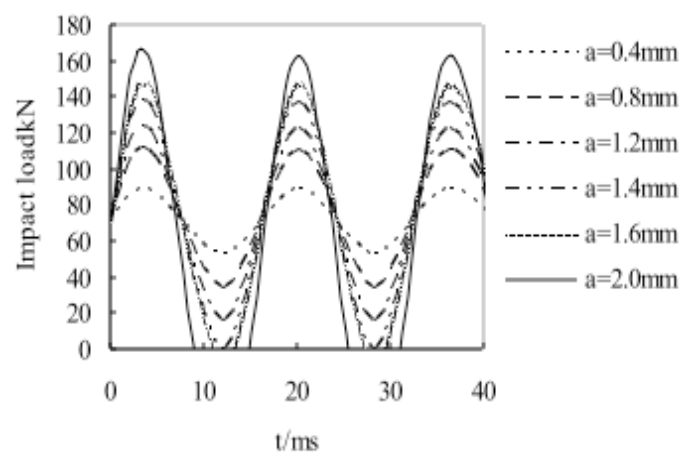

Figure 6. Wheel-rail impact force versus wheel ovaliation extent

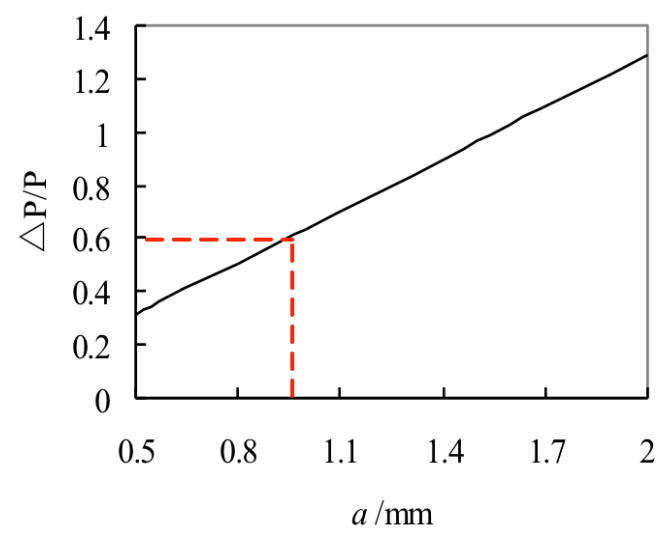

Figure 7. Safety threshold of wheel ovalization 


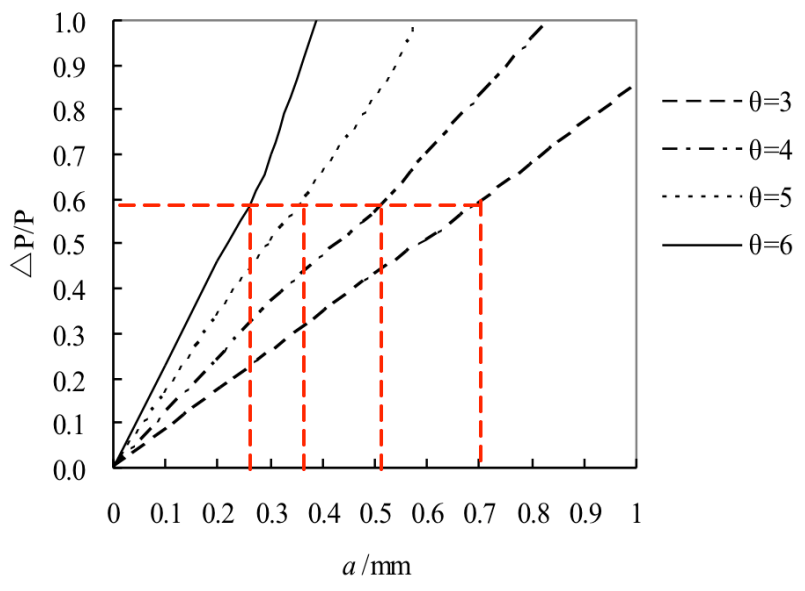

Figure 8. Safety threshold of wheel polygonalization amplitude

\section{CONCLUSIONS}

Peak impact forces caused by periodic OOR wheels vary strongly with train speed. In high speed operations, out-of-round wheels cause severe damage to both track and vehicle components such as sleepers, rails, wheelsets and bearings. They also lead to increased impact and rolling noise levels and to discomfort for passengers owing to high vibration amplitudes. There is a trend towards a higher exploitation of track infrastructure and rolling stock owing to increasing numbers of wheelset passages in conjunction with higher train speeds and axle loads. Based on characteristic of wheel/rail dynamic interaction forces caused by OOR railway wheels, it is able to detect OOR wheel when the measured peak wheel/rail interaction force exceeds the limit impact load level. The study is very important for enhancing the stability and economy signification of rail transmission.

TABLE I.

CRITERION FOR OOR WHEEL IDENTIFICATION

\begin{tabular}{|c|c|c|c|}
\hline & OOR & wheel-rail impact loads & safety threshold ( $a$ : OOR amplitude; $\theta$ : OOR order) \\
\hline & wheelflat & impulsive impact & depth less than $1.5 \mathrm{~mm}$, length less than $70 \mathrm{~mm}$ \\
\hline & long local defect & harmonic vibration & $\begin{array}{c}a \leq 0.95 \mathrm{~mm}(v=250 \mathrm{~km} / \mathrm{h}) ; a \leq 0.8 \mathrm{~mm}(v=300 \mathrm{~km} / \mathrm{h}) ; \\
a \leq 0.7 \mathrm{~mm}(v=350 \mathrm{~km} / \mathrm{h}) .\end{array}$ \\
\hline \multirow{3}{*}{$\begin{array}{c}\text { polygonal } \\
\text { wheel }\end{array}$} & first order polygonalization & & eccentricity $r \leq 1.5 \mathrm{~mm}(v=350 \mathrm{~km} / \mathrm{h})$ \\
\hline & second order polygonalization & continuous periodic harmonic vibra- & $a: 0.9 \sim 1.0 \mathrm{~mm}(v=300 \mathrm{~km} / \mathrm{h})$ \\
\hline & other order polygonalization & tion & $\begin{array}{c}a \leq 0.7 \mathrm{~mm}(\theta=3) ; a \leq 0.5 \mathrm{~mm}(\theta=4) ; a \leq 0.35 \mathrm{~mm}(\theta=5) ; \\
a \leq 0.25 \mathrm{~mm}(\theta=6) ; a \leq 0.2 \mathrm{~mm}(\theta>6) .\end{array}$ \\
\hline
\end{tabular}

\section{REFERENCES}

[1] J. C. O. Nielsen and A. Johansson. "Out-of-round railway wheels a literature survey," Proceedings of the Institution of Mechanical Engineers, Part F: Journal of Rail and Rapid Transit, vol. 214, 2000, pp79-91. http://dx.doi.org/10.1243/0954409001531351

[2] D. W. Barke and W. K. Chiu. "A review of the effects of out-ofround wheels on track and vehicle components," IMechE Journal of Rail and Rapid Transit, vol. 219, 2005, pp 151-175.

[3] X. S. Xue, J. B. Xiao and X. S. Jin. "Influence of High Speed Railway W heels Ovalization on Vehicle Lateral Stabilit," Chinese Journal of Mechanical Engineering, vol. 44, 2008, pp 50-56. http://dx.doi.org/10.3901/JME.2008.03.050

[4] R. Luo, J. Zeng, P. B. Wu, et al. "Simulation and Analysis of Wheel Out-of-roundness Wear of High-speed Train," Journal of The China Railway Society, vol.32, 2010, pp 30-35

[5] J. C. O. Nielsen, R. Lunden and A. Johansson. "Train-track interaction and mechanisms of irregular wear on wheel and rail surfaces," Vehicle System Dynamics, vol. 40, 2003, pp 3-54. http://dx.doi.org/10.1076/vesd.40.1.3.15874

[6] A. Johansson and C. Andersson. "Out-of-round railway wheels A study of wheel polygonalization through simulation of threedimensional wheel-rail interaction and wear," Vehicle System Dynamics, vol. 43, 2005, pp 539-559. http://dx.doi.org/10.1080/ $\underline{00423110500184649}$
[7] X. S. Zhang, X. B. Xiao and X. S. Jin. "Effect of ovalization of high speed railway wheels on vehicle dynamic performance," Journal of Mechanical Engineering, vol. 46, 2010, pp 67-73. http://dx.doi.org/10.3901/JME.2010.16.067

[8] A. Johansson. "Out-of-round railway wheels - assessment of wheel tread irregularities in train traffic," Journal of Sound and Vibration, vol. 293, 2006, pp 795-806. http://dx.doi.org/10.1016/ j.jsv.2005.08.048

\section{AUTHORS}

Ying SONG is with the Transportation Institute, Shijiazhuang Tiedao University, Shijiazhuang, CO 050043 China (e-mail: sy8112@126.com).

Zhichen WANG (Corresponding Author) is with the Shijiazhaung Tiedao University, Shijiazhuang, CO 050043 China (e-mail: zczc1100@126.com).

This project was supported by the National Natural Science Foundation of China (No.51208318), the Hebei Province Natural Science Foundation of China (No. E2011210032), and the Hebei Educational Scientific Research Project of China(No. Q2012025). This article is an extended and modified version of a paper presented at the 2012 International Conference on Artificial Intelligence and Its Application in Industry Production (AIAIP 2012), held in Wuhan, China in December 2012. Manuscript received 19 May 2013. Published as resubmitted by the authors 26 June 2013. 